\title{
11 Scientific imperialism and explanatory appeals to evolution in the social sciences
}

\author{
Stephen M. Downes
}

\section{Introduction}

In this chapter I focus on what the charge of scientific imperialism amounts to and whether the charge is (always) appropriate in the case of the relation between evolutionary biology and the social and behavioral sciences. I will then briefly introduce two very different examples of this relationship: evolutionary psychology and evolutionary linguistics. Here I hope to support the claim that relations between evolution and the study of human behavior are not all created equal. Next I move to a discussion of scientific imperialism and the way in which the concept has been proposed, developed and defended. Here I focus on John Dupré's account of scientific imperialism, as this account was developed to critically assess evolutionary psychology (along with economics). I go on to propose an empirically based approach to scientific change that I hope can help in identifying the strengths and limitations of appeals to scientific imperialism. Here I will draw on an analogy between the ways in which empirical approaches to scientific change helped refine the notion of scientific revolutions and the ways in which related empirical approaches may help refine our notion of scientific imperialism.

My interest in scientific imperialism stems from claims like this made by John Dupré: "Evolutionary psychology can be seen as a failed imperialist adventure from evolutionary biology" (Dupré 2001, 16). I have critically appraised evolutionary psychology from a number of different perspectives (see e.g. Downes 2015), and when I first encountered Dupré's charge of imperialism I assumed that he was invoking an independent critical perspective on evolutionary psychology. Here I will reassess this initial assumption. There are several issues that are relevant to this reassessment. First, evolutionary psychology is a quite distinct "adventure" from evolutionary biology. There are other applications of aspects of biological theory in the social and behavioral sciences that raise very few eyebrows and do not seem to warrant the charge of imperialism, where "imperialism" is understood as a pejorative term. Second, there are many critics of evolutionary psychology who criticize it on the grounds that its proponents do not pay enough attention to evolutionary biology and many base their critical attacks on evolutionary psychology in evolutionary theory. Third, the very 
notion of scientific imperialism has undergone some serious critical appraisal. There are many promising analyses of scientific imperialism but there are still plenty of issues unresolved (many of these issues are confronted in other chapters in this volume). For example, if scientific imperialism is used in a pejorative sense, is the charge an epistemic one or a moral one? Further, when we discuss change in science in terms of scientific imperialism, are we discussing an issue internal or external to science?

This latter issue invokes discussion of another political metaphor in philosophy of science, Thomas Kuhn's scientific revolutions (Kuhn 1962). I propose that discussion of the metaphor of scientific imperialism in relation to empirical work on scientific change can be as productive as discussion of Kuhn's famous metaphor of revolutions in relation to relevant empirical work. Finally, I touch on the broader connections between empirical work, in the sociology of science, for example, and the epistemic appraisal of scientific work. Can we say that a given piece of scientific work is bad on the basis of an assessment of the institutional practices scientists engage in without any detailed examination of the relevant hypotheses and the testing of those hypotheses? Is it possible to completely distinguish the assessment of institutional practice from epistemic appraisal?

\section{Evolution and the social sciences}

In the conclusion of The Origin of Species, Charles Darwin says: "In the distant future I see open fields for far more important researches. Psychology will be based on a new foundation, that of the necessary acquirement of each mental power and capacity by gradation. Light will be thrown on the origin of man and his history" (see e.g. Downes 2015). Darwin went on to write the Descent of Man and The Expression of the Emotions in Man and Animals, delivering on his promise rather than waiting for researchers in a distant future. Now, almost every avenue of social and behavioral science has an evolutionary branch or shows the influence of some kind of evolutionary thinking. Evolutionary anthropology is a well-established part of anthropology with several in field journals and one or two entire departments dedicated only to this mode of anthropological research. In cognitive psychology, a large percentage of hypotheses are accompanied by some evolutionary speculation, such as to postulate that the psychological mechanism of interest is part of the evolutionarily older part of the brain. Dual process theory in cognitive psychology is presented against the background of loosely evolutionary considerations. In the last ten years, consumer studies researchers have proposed a reworking of their field that draws upon evolutionary ideas.

The kind of evolutionary thinking invoked in the wide range of social sciences varies greatly. Also the ways in which the relevant evolutionary thinking is brought into the different social sciences varies greatly, as does the source of the relevant evolutionary thought. This variation should be of great interest to all of us interested in scientific imperialism and especially those of us who aim 


\section{Stephen M. Downes}

to understand the introduction of evolutionary ideas into the social sciences as a case of scientific imperialism. I only lay out two brief examples of evolutionary social sciences here, but I hope that the contrast between the two adequately illustrates these points. I will briefly discuss the well-known field of evolutionary psychology and then turn to a likely less familiar sub-discipline of the larger field of evolutionary linguistics.

\section{Evolutionary psychology}

Evolutionary psychology was proposed and defended by a number of different researchers in the late 1980s. Proponents of evolutionary psychology included anthropologists and psychologists along with human sociobiologists and others who studied human behavior. Some key experiments were championed by evolutionary psychologists as providing strong support for evolutionary hypotheses about the way the human mind works and leading thinkers in the field produced theoretical papers, and subsequently books, to lay out the key theoretical tenets and methodologies of the new field. Examples of this early experimental work include David Buss (1989) on mate selection, Leda Cosmides (1989) on cheater detection and Devendra Singh (1993) on women's waist/hip ratio preferences in men. Theoretical work included John Tooby and Cosmides's (1992) long position paper on evolutionary psychology, which they shortened into the still highly cited and much more accessible primer on Evolutionary Psychology (1997), and papers by Buss. Buss also wrote the first evolutionary psychology textbook (1999) and edited The Handbook of Evolutionary Psychology (2005).

Evolutionary psychology has always been highly visible, thanks in large part to the success of popular works championing the field. Robert Wright's The Moral Animal: Why We Are the Way We Are: The New Science of Evolutionary Psychology (1994) and Steven Pinker's How the Mind Works (1997) are hugely popular works. Each author provides nice, accessible introdu (1) to evolutionary psychology and also vehemently attacks all work or une social and behavioral sciences that does not appeal to evolution or, worse still, that is in direct opposition to evolutionary approaches. There are many other popular evolutionary psychology books and several of these are highly controversial and provocative. Books such as Randy Thornhill and Craig Palmer's A Natural History of Rape: Biological Bases of Sexual Coercion (2000) and Buss's The Murderer Next Door: Why The Mind is Designed to Kill (2005) proved incredibly controversial and are lightning rods for much of the backlash against evolutionary psychology.

Taking a look at Buss's (1995) theoretical paper and Clark Barrett's (2015) recent book helps us understand what evolutionary psychologists proposed at the outset and reveals the central tenets of the now somewhat more mature field. Buss challenges his colleagues in psychology, saying: "Psychological science is currently in conceptual disarray, characterized by unconnected minitheories and isolated empirical findings. [...] Evolutionary psychology provides 
the conceptual tools for emerging from this fragmented state" (Buss 1995, 1). The relevant conceptual tools include treating the human mind as a collection of adaptations that were selected to solve the various adaptive problems our ancestors faced.

Understanding organs as adaptations is a key component of evolutionary biology. Darwin countered design theorists such as Paley by defending the view that an organ as complex as the human eye could arise as the result of gradual modification, guided by selection, over huge stretches of time. Adapting Darwin, evolutionary psychologists propose that we understand the mind as a collection of highly adapted mental organs and we account for the existence of these mental organs by appealing to adaptation or natural selection. Evolutionary psychologists argue that this account of the human mind better explains the results of experiments on human preferences and on human reasoning. Singh's work on waist/hip ratio preferences in men involves first showing a convergence on a particular preferred waist/hip ratio and then explaining this convergence by appealing to an evolved mental mechanism that helps men achieve success in mate selection (see e.g. Singh 1993). Buss provides this assessment of the promise of evolutionary psychology:

From the perspective of evolutionary psychology, many traditional disciplinary boundaries are not merely arbitrary but are misleading and detrimental to progress. They imply boundaries that cleave mechanisms in arbitrary and unnatural ways. Studying human psychology via adaptive problems and their solutions provides a natural means of "cleaving nature at its joints" and hence crossing current disciplinary boundaries.

(Buss 1995, 1)

Assessing the current state of play in evolutionary psychology 20 years after Buss's paper, Barrett says: "Unfortunately, the rise of evolutionary psychology has led to rampant generation of evolution-flavored hypotheses throughout the social sciences, not all of which pass basic tests of evolutionary plausibility" (Barrett 2015, 12). Barrett claims: "When done properly, evolutionary psychology is just evolutionary biology applied to the mind" (ibid., 12). Barrett's aim is to realign evolutionary psychology with evolutionary thinking in general. He argues that "not all evolutionary hypotheses are created equal, and that careful thinking about how evolution actually works [...] can get you a long way" (ibid., 12), and aims to provide "an evolutionary psychology grounded as rigorously as possible in the logic of biology - the logic of evolution - and no other" (ibid., 12). Barrett is convinced that "the fact that human minds are products of evolution is something that we can be as sure of as any other fact in biology" (ibid., 12). Echoing Buss, Barrett claims that evolutionary models are far preferable "than the currently rather impoverished set of models in psychology" (ibid., 12). Evolutionary psychologists claim to offer their colleagues in psychology and other social sciences a stronger explanatory repertoire that can account for a wide range of phenomena. 


\section{Stephen M. Downes}

\section{Evolutionary linguistics}

I now turn to a contrasting example of work in the social sciences influenced by evolution: Russell Gray and his colleagues' work on human migration in the Pacific (Gray et al. 2009; Gray and Jordan 2000). In the 1990s there were two main hypotheses about the original human settlement of the Micronesian and Polynesian Pacific islands and neighboring areas. One hypothesis is that this settlement process was quite rapid. This is referred to as the "express train" hypothesis. The other hypothesis is of a slower and less direct migration pattern with looping and backtracking, sometimes referred to as the "entangled bank" model. Linguists have observed that the inhabitants of the Pacific all share related languages. Gray proposed that quantitative phylogenetic techniques could be applied to the analysis of languages and tree structures relating relevant languages could be proposed and tested. In phylogenetics, trees are produced to assess hypotheses about relations between segments of DNA. Gray observes that languages have a syntactic structure that is amenable to similar analysis. Gray notes that despite the parallels between biological and linguistic evolution, before him, no linguists had appealed to the "quantitative phylogenetic methods that have revolutionized evolutionary biology in the last 20 years" (Gray and Jordan 2000, 1052; Gray et al. 2009).

Gray and his colleagues produced several trees and assessed the best trees for the language data sets using statistical methods from quantitative phylogenetics. In their first work of this kind, they found that the topology of their language tree "was highly compatible with the express train model" (Gray and Jordan 2000, 1052). In more recent work, they developed language trees that were compatible with the "pause-pulse" model of human settlement as opposed to its main competitor, the "slow-boat diffusion" model. Gray and his colleagues exploit the similarity between lexical items and sections of DNA and use the techniques from evolutionary biology used to discover relations between sections of DNA. At this stage of the work, there are no grand claims about the applicability of evolution to all of linguistics or other areas of social science. Rather, Gray and his colleagues have introduced a technique from evolutionary biology into one area of work in linguistics and the study of early human migration. There is potential for the application of phylogenetic analysis to other aspects of human cultural evolution, and Fiona Jordan (see e.g. Jordan 2013) has made some cautious forays into this area.

\section{Scientific imperialism}

I now turn to scientific imperialism. Recall that my interest in scientific imperialism was sparked by Dupré's claim that "[e]volutionary psychology can be seen as a failed imperialist adventure from evolutionary biology" (Dupré 2001, 16). My focus therefore will be on Dupré's notion of scientific imperialism. My understanding of Dupré's notion of scientific imperialism has been greatly helped by work by Steve Clarke and Adrian Walsh (2009, 2013), and Uskali Mäki (2009, 2013), and their influence will be seen in what follows here. 
Dupré says that scientific imperialism is "the tendency for a successful scientific idea to be applied far beyond its original home, and generally with decreasing success the more its application is expanded" (Dupré 2001, 16). I agree with Clarke and Walsh (2009) that Dupré uses imperialism in a pejorative sense and also agree with them that this is clearly a political metaphor used in the service of understanding science. The most familiar political metaphor in the philosophy of science is Kuhn's (1962) scientific revolution. I return to scientific revolutions below. Clarke and Walsh (2009) emphasize the normative dimension of Dupré's scientific imperialism. They express this normative dimension as follows: "In the human sciences, scientific imperialism raises an additional concern, which is that important human values could fail to be expressed, and we might become the sorts of people that, on reflection, we would not wish to have become" (Clarke and Walsh 2009, 205). I agree that Dupré is concerned that scientizing the study of human behavior can lead to a lack of appreciation for values but I also think that there is a strongly epistemic normative component to Dupré's charge of scientific imperialism. He thinks that scientific imperialism produces bad science not just science that leads us to devalue ourselves. Mäki asks an important question in this context too: is evolutionary psychology bad science independent of any considerations about scientific imperialism (Mäki 2013, 238)? Dupré certainly has argued on independent grounds that evolutionary psychology is bad science but I take him also to be arguing that it is bad science because of its imperialism. Let us look at Dupré's version of scientific imperialism in a little more detail to see if this holds up.

Dupré says "imperialistic economics is a deliberate attempt to import the perspective of economics into many diverse facets of human behavior" (Dupré 2001, 16). I think he would be happy with the following reworking of this claim: imperialistic evolutionary psychology is a deliberate attempt to import the perspective of evolutionary biology into many diverse facets of human behavior. According to Dupré, the problem here is that the imperialist imposes a general structural, or scientific theoretical, perspective irrespective of the nuances of context. He goes on to spell this out by discussing structure. The idea is that if you take yourself to have an account of the underlying structure of something, say human beings, you apply that structural account whenever you come across a human being. Dupré says that taking note of the relevant context will undermine such structural accounts and they will be "doomed to failure" (ibid., 16). The positive side to Dupré's proposal is pluralism, which he contrasts with imperialism. He says that we cannot properly understand any central features of human life from "any unique and homogeneous perspective" and " $[\mathrm{t}]$ he moral of pluralism, therefore, is not to point to better ways of doing science $[. .$.$] but to show the limits of science, at least in its application to the$ complexities of human life" (ibid., 17). Dupré admits that what he takes to be a problem with imperialist ventures in science is for others a mark of their success and what makes them attractive to their adherents. For example, he thinks that what attracts people to evolutionary psychology is its "claims to breadth of application" (ibid., 81). He also says that "[o]bvious rewards and attractions 


\section{Stephen M. Downes}

accrue to the pursuit of scientific ideas with the greatest claims to generality of application" (ibid., 84). Dupré is not just concerned with generality understood in terms of the wide scope of application of the imperialist science but also in the sense that imperialist sciences stay above the level of what matters empirically. Evolutionary psychologists' "most imperialistic moments," he says, "are also the moments at which they are most inclined to substitute purely formal demonstrations of possibility for the hard work of demonstrating actuality" (ibid., 138). Perhaps the following characterization, which I have adapted from Mäki's analysis of imperialist economics, best captures Dupré's scientific imperialism:

Evolutionary psychology is an example of scientific imperialism as it is the result of scientific expansionism of evolutionary biology. Evolutionary psychology locates new types of explanandum phenomena in psychology and other social sciences, and evolutionary psychology presents itself hegemonically as being in possession of superior theories and methods, thereby excluding rival theories and approaches from consideration.

(adapted from Mäki 2009, 374)

Further, Dupré takes the newly imported theories to be mistaken in various ways and hence detrimental to psychology and other social sciences. This assessment is made on independent grounds from the attribution of imperialism but bringing mistaken theories to bear renders the imperialism more pernicious.

Dupré presents what I take to be a somewhat different view of scientific imperialism from the one outlined above when he says the following: "whether it is from commendable epistemological enthusiasm, or from the desire to become rich and famous through writing best selling books, the tendency to exaggerate the scope of the theory with which one is professionally engaged is a familiar aspect of scientific life. I referred to this phenomenon above as scientific imperialism" (Dupré 2001, 82, emphasis added). This seems to be a distinct notion from the one we have been focusing on so far. Clearly this notion is related but it pertains to popularizers of imperialistic science rather than practitioners. He gives examples: "physicists envisage final theories of everything, and not surprisingly these turn out to be physical theories" and "Darwinians, or their camp-followers, make almost equally ambitious claims. Recall the remark from Dennett [...] 'Darwin's dangerous idea is reductionism incarnate, promising to unite and explain almost everything in one magnificent vision" (ibid., 82). I agree that popularizers of various sciences tend to exaggerate their scope of application but I take the charge of scientific imperialism to be part of an epistemic criticism of the relevant science rather than part of a critical appraisal of popular science writing. It is certainly annoying when popular science writers exaggerate and misrepresent the claims of the scientists they promote but the relevant scientists are not directly responsible for these exaggerated claims. There are many popular works that focus on sciences that promote easily digestible and widely applicable general ideas and so the 
approach to science may influence its broad appeal. It should be noted, though, that there are also bestsellers, for example, Stephen Hawking's A Brief History of Time (1988), whose content is completely obscure to most lay readers and yet sales indicate that this work has wide appeal. A detailed sociological examination of evolutionary psychology will doubtless reveal various connections between popular works on progress in the field and actual practice in the lab. For now, though, I want to focus just on Dupré's narrower version of scientific imperialism, characterized in Mäki's terms.

\section{Empirical challenges for claims of imperialism}

Kuhn (1962) characterizes scientific change in terms of scientific revolutions. We all grasp the outlines of Kuhn's view. A period of normal science guided by a paradigm starts to break down and a period of revolutionary science takes over. Many philosophers of science argue that Kuhn's approach to scientific change is irrationalist or arational, but many in history and sociology of science are not as worried about this issue and focus more on the facts on the ground in times of scientific change. The issues here are the extent to which Kuhn's characterization fits with the way in which actual theory change occurs in science or the way in which theory change has occurred in specific instances in the history of science. Mäki asks "what does it take to empirically identify instances of scientific imperialism?" (Mäki 2013, 338). As he points out, though, there are currently a number of different notions of scientific imperialism. Rather than trying to identify instances of scientific imperialism empirically, I propose comparing particular versions of scientific imperialism to the relevant empirical facts in their specific domain of application. I focus on some of Dupré's claims about evolutionary psychology as an imperialist venture and contrast them with some empirical observations about the field. First, I briefly outline an analogous move directed at Kuhn.

One question about scientific change is how the new theory/paradigm/ research program, etc. can take hold when the folks who held the old view are still around. Kuhn held that Planck's principle was explanatorily relevant here. Planck said that new theories do not come to the fore because opponents to the theory come to accept it, but rather the opponents die off. A related idea of Planck's, popular among many scientists and historians and philosophers of science, is that younger scientists take up newer ideas more readily. David Hull and his collaborators (Hull et al. 1978) point out that these claims are open to empirical test, as the birth and death records of scientists throughout history are readily available. Hull also points out that it is more difficult to assess when scientists come to adopt "various positions on scientific issues," but not impossible. Hull focuses on the incredibly rapid adoption of Darwin's ideas in Britain shortly after the publication of The Origin of Species. In a mere ten years after the publication of The Origin of Species, Darwin's ideas had become dominant. Not all relevant scientists accepted Darwin's ideas after ten years, but Hull's finding is that "age explains less than 10 percent of the variation in 


\section{Stephen M. Downes}

acceptance" (ibid., 202). The Darwinian revolution may have come about due to extra-scientific factors but Hull reveals that the age of scientists was not one of the most important factors.

Dupré makes a number of claims about the imperialism of evolutionary psychology that are open to empirical investigation. One is that evolutionary psychology is an "imperialist adventure from evolutionary biology" (Dupré 2001, 16). Evolutionary psychologists certainly couch their claims in evolutionary language but the most consistent criticism of evolutionary psychology since its inception is one or other version of the claim that evolutionary psychologists do not have the biology right. A related criticism is that evolutionary psychologists do not carry out experiments that confront evolutionary hypotheses. Evolutionary biologists have been some of the harshest critics of evolutionary psychology. John Maynard Smith claimed that evolutionary psychologists had not produced any models that were ready for appropriate testing. Richard Lewontin has argued that evolutionary psychologists employ an impoverished notion of adaption, and Jerry Coyne (see e.g. Coyne 2009) attacks evolutionary psychology on a number of evolutionary grounds. Clark Barrett's (2015) recent assessment of evolutionary psychology includes voicing concerns over how far from evolutionary theory his evolutionary psychology colleagues have strayed. Perhaps evolutionary psychology is an imperialist venture but it is a homegrown one. The appropriate political metaphor here is perhaps a coup, a movement cooked up by insiders using what they take to be the conceptual tools of a field that they admire. If the empire is not backing your adventure, it is perhaps not an imperialist adventure.

As we have seen, Dupré sees a connection between ideas with general applicability and imperialist moves in science. He also says "[o]bvious rewards and attractions accrue to the pursuit of scientific ideas with the greatest claims to generality of application" (Dupré 2001, 84). This sounds right, but like Planck's claims about science, it is also amenable to empirical investigation. One way in which we can measure both the rewards an idea accrues and its attractiveness is via citation analysis. If we assume for now that this is a reasonable measure, let us use it to test Dupré's claim. Recent research on the most-cited work of all time reveals a rather surprising result with respect to the generality of scientific work (Van Noorden et al. 2014). The most-cited paper of all time is a paper describing an assay for determining the amount of protein in a solution. No groundbreaking theoretical papers in any field, such as theoretical work leading to Nobel Prizes, come anywhere close to the top 100 most-cited papers. The top 100 papers are overwhelmingly those characterizing biological techniques (see Figure 11.1, for more data such as this). Certainly some of this work has led to Nobel Prizes but none of this work is paradigmatically general. The work certainly has wide applicability in experimental contexts and is tremendously useful but it is not work of the scope of the General Theory of Relativity. Citation analysis is only one way to measure the success and attractiveness of scientific ideas but if we use citations as an index of success, generality is not the route to success in science. It should be noted that 
Format: Royal $(156 \times 234 \mathrm{~mm})$; Style: A; Font: Bembo;

Dir: P:/Frontlist Production Teams/eProduction/Live Projects/9781138059344/ dtp/9781138059344 text.3d;

citation analysis does not provide clear access to epistemic success. For example, increased citation count could simply mean increased popularity. However, there are good reasons to believe that scientific works are cited, for the most part, for their scientific content. This indicates that we should have some confidence in the conclusion here that generality is not a sure route to success in science.



Figure 11.1 


\section{Stephen M. Downes}

I have no doubt that various non-epistemic factors play an important role in sustaining evolutionary psychology but I am skeptical that evolutionary psychology is sustained by evolutionary biologists and I am also skeptical that it is successful because its ideas have general applicability. It may be true that evolutionary psychology has popular appeal because it appears to be based in evolutionary biology and, when sloganized, its central ideas seem widely applicable. As I mentioned above, though, I think that the popular uptake of a given scientific field is neither a measure of its success nor a mark of the extent to which it is imperialist.

\section{Conclusion}

If the evidence supports my claim that evolutionary psychology is not supported by evolutionary biology and is therefore not best understood as an "adventure from evolutionary biology," perhaps that component can be dropped from our characterization of Dupré's scientific imperialism. Recall, I borrowed from Mäki to give this characterization: "Evolutionary psychology is an example of scientific imperialism as it is the result of scientific expansionism of evolutionary biology. Evolutionary psychology locates new types of explanandum phenomena in psychology and other social sciences, and evolutionary psychology presents itself hegemonically as being in possession of superior theories and methods, thereby excluding rival theories and approaches from consideration" (adapted from Mäki 2009, 374). Here is a characterization without the clause about expansionism from evolutionary biology: "Evolutionary psychology is an example of scientific imperialism as it locates new types of explanandum phenomena in psychology and other social sciences, and evolutionary psychology presents itself hegemonically as being in possession of superior theories and methods, thereby excluding rival theories and approaches from consideration." This perhaps better captures the activity of evolutionary psychologists on the ground, but without the expansionist component, does this adequately capture scientific imperialism? Is a hegemonic approach coupled with a broadening of the scope of application and excluding rival theories sufficient for imperialism?

Evolutionary psychology is clearly a very different endeavor from the type of evolutionary linguistics I introduced earlier. Evolutionary psychologists are very confrontational in their approach to their fellow social scientists and much of their work has a triumphal air to it. Even Barrett, who is relatively moderate in his approach, champions evolutionary psychology over the "impoverished set of models in psychology" (Barrett 2015, 12). I am not sure if refining our notion of scientific imperialism will help us better understand a field like evolutionary psychology. Perhaps other related political metaphors are more appropriate in this context. I do think that careful empirical analysis of evolutionary psychology, such as citation analysis, may reveal more about the dynamics of the field and help us understand its success in the face of apparently cogent and damaging criticism of its central ideas. In contrast, evolutionary linguistics appears not to be a candidate for scientific imperialism in Dupré's 
terms. The evolutionary linguists considered above do not present their approach in order to exclude rivals, and display none of the hegemonic tendencies Dupré sees in evolutionary psychology. The case of evolutionary linguistics does reveal problems for Dupré, as if scientific imperialism in this domain simply consisted in transporting evolutionary views into social science, then it too would be imperialist. To rule out evolutionary linguistics as a case of imperialism requires stressing the clause about excluding rival theories and approaches. Finally, the introduction of careful empirical analysis - such as citation analysis - of any proposed imperialist science should help the philosophical task of better characterizing scientific imperialism.

\section{References}

Barrett, H.Clark. 2015. The Shape of Thought: How Mental Adaptations Evolve. Oxford: Oxford University Press.

Buss, David M. 1989. "Sex Differences in Human Mate Preferences: Evolutionary Hypotheses Tested in 37 Cultures." Behavioral and Brain Sciences 12: 1-49.

Buss, David M. 1995. "Evolutionary Psychology: A New Paradigm for Psychological Science.” Psychological Inquiry, 6: 1-30.

Buss, David M. 1999. Evolutionary Psychology: The New Science of the Mind. Boston: Allyn and Bacon.

Buss, David M. 2005a. The Murderer Next Door: Why the Mind is Designed to Kill. New York: Penguin.

Buss, David M. (ed.). 2005b. The Handbook of Evolutionary Psychology. Hoboken, NJ: Wiley.

Clarke, Steve and Adrian Walsh. 2009. "Scientific Imperialism and the Proper Relations between the Sciences." International Studies in the Philosophy of Science 23: 195-207.

Clarke, Steve and Adrian Walsh. 2013. "Imperialism, Progress, Developmental Teleology, and Interdisciplinary Unification." International Studies in the Philosophy of Science 27: 341-351.

Cosmides, Leda. 1989. "The Logic of Social Exchange: Has Natural Selection Shaped How Humans Reason? Studies with the Wason Selection Task." Cognition 31: 187-276.

Coyne, Jerry A. 2009. Why Evolution is True. New York: Viking.

Downes, Stephen M. 2015. "Evolutionary Psychology, Adaptation and Design." In Thomas Heams, Philippe Huneman, Guillaume Lecointre and Marc Silberstein (eds). Handbook of Evolutionary Thinking in the Sciences. Dordrecht: Springer, pp. 659-673.

Dupré, John. 2001. Human Nature and the Limits of Science. Oxford: Oxford University Press. Gray, Russell D., Alexei J. Drummond and Simon J. Greenhill. 2009. "Language Phylogenies Reveal Expansion Pulses and Pauses in Pacific Settlement." Science 323: 479-483.

Gray, Russell D. and Fiona M. Jordan. 2000. "Language Trees Support the Expresstrain Sequence of Austronesian Expansion." Nature 29: 1052-1055.

Hawking, Stephen. 1988. A Brief History of Time. New York: Bantam Books.

Hull, David L., Peter D. Tessner and Arthur M. Diamond. 1978. "Do Young Scientists Accept New Ideas with Greater Alacrity than Older Scientists?” Science 202: 717-723.

Jordan, Fiona M. 2013. "Comparative Phylogenetic Methods and the Study of Pattern and Process in Kinship." In Patrick McConvell, Ian Keen and Rachel Hendery (eds). Kinship Systems: Change and Reconstruction. Salt Lake City: University of Utah Press, pp. 43-58. 


\section{Stephen M. Downes}

Kuhn, Thomas. 1962. The Structure of Scientific Revolutions. Chicago: University of Chicago Press.

Mäki, Uskali. 2009. "Economics Imperialism." Philosophy of the Social Sciences 39: 351380 .

Mäki, Uskali. 2013. "Scientific Imperialism: Difficulties in Definition, Identification, and Assessment." International Studies in the Philosophy of Science 27: 325-339.

Pinker, Steven. 1997. How the Mind Works. New York: W.W. Norton.

Singh, Devendra. 1993. "Adaptive Significance of Female Physical Attractiveness: Role of Waist-to-Hip Ratio.” Journal of Personality and Social Psychology 65: 293-307.

Thornhill, Randy and Craig T. Palmer. 2000. A Natural History of Rape: Biological Bases of Sexual Coercion. Cambridge, MA: MIT Press.

Tooby, John and Leda Cosmides. 1992. “The Psychological Foundations of Culture." In Jerome H. Barkow, Leda Cosmides and John Tooby (eds). The Adapted Mind. New York: Oxford University Press, pp. 19-136.

Tooby, John and Leda Cosmides. 1997. Evolutionary Psychology: A Primer. Santa Barbara: University of California. www.psych.ucsb.edu/research/cep/primer.html.

Van Noorden, Richard, Brendan Maher and Regina Nuzzo. 2014. "The Top 100 Papers." Nature 514: 550-553.

Wright, Robert. 1994. The Moral Animal. Why We Are the Way We Are: The New Science of Evolutionary Psychology. New York: Vintage Books. 